\title{
Evaluation of Performance and Yield Stability Analysis Based on AMMI and GGE Models in Introduced Upland Rice Genotypes Tested Across Northwest Ethiopia
}

\author{
Taddesse Lakew $^{1 *}$, Abebaw Dessie ${ }^{1}$, Sewagegne Tariku $^{2}$, Desta Abebe $^{3}$ \\ ${ }^{1}$ Fogera National Rice Research and Training Centre, ${ }^{2}$ Adet Agricultural Research Center, \\ ${ }^{3}$ Pawe Agricultural Research Centre
}

\begin{abstract}
Multi-environment rice evaluation trials were conducted in eight environments across Northwest Ethiopia to select promising varieties that can be cultivated by farmers. Sixteen upland rice genotypes were planted in a randomized complete block design of three replications in each location. Data were analyzed using combined analysis of variance, Additive Main Effects and Multiplicative Interaction (AMMI) and GGE bi-plot analysis. The MMI analysis of variance for grain yield $\left(\mathrm{kg} \mathrm{ha}^{-1}\right)$ of 16 upland rice genotypes revealed that the main effects of genotypes $(G)$ and environments $(E)$ accounted for $53.8 \%$ and $26.8 \%$ of the treatment SS, respectively. The $G \times E$ interaction also accounted for $19.4 \%$ of the treatment SS. The mean grain yield value of genotypes averaged over environments indicated that WAB450-1-B-P-462-HB (G11) had the highest (4085.8 $\left.\mathrm{kgha}^{-1}\right)$, followed by ARCCU3Fa11-L1P1-B-B-1 (G4) and ARCCU2Fa11-L2P1-B-B-1(G9) with grain yield of 3975.8 and $3853.3 \mathrm{kgha}^{-1}$,respectively. As revealed by AMMI and GGE bi-plots, the genotype G11 was identified as specifically adapted to Fogera (Woreta areas). Following evaluation of candidate genotypes (G11, G4 and G9) and collecting farmers feedback, the National Variety Release Committee also recommended G11 as variety for cultivation in Fogera and other areas of similar cultivation conditions.
\end{abstract}

Keywords: Upland rice, AMMI, GGE bi-plot, $G \times$ E interaction.

\section{INTRODUCTION}

Compared to other African countries, rice cultivation in Ethiopia is a recent phenomenon, most probably started in the late 1960s. Currently, the crop showed increasing trends in terms of area, total production and productivity. The country has a highly potential land of 5 million ha for rain fed rice cultivation [1]. In Ethiopia, rice is used in the preparation of local foods such as injera, dabbo, genffo, kinchie and shorba [2]. Moreover, the crop is means of employment and income source to the farming community. Low productivity, diseases occurrence and erratic rain fall pattern are rice production constraints in Ethiopia. Low productivity, mainly in the upland rice production system, is attributed to, among other things, lack of high yielding varieties, terminal moisture stress and low soil fertility [1]. In Ethiopia, multi-environment variety trials have been conducted primarily to identify high yielding varieties of wider adaptation that are early maturing and resistant to major diseases of rice. Multi-environment trials allow breeders to select the best-performing genotype for their target regions by assessing the relative performance of genotypes under a variety of locations and environmental conditions [3].

Genotypes tested in different locations and over years have significant fluctuations in yield due to variations in soil fertility, unpredicted rainfall and presence of other biotic and abiotic stresses [4]. Such differential response of genotypes to different environmental conditions is termed as genotype by environment interaction (GEI). GE interaction reduces the genetic progress in plant breeding programs through minimizing the association between phenotypic and genotypic values [5]. Hence, GE interaction must be either exploited by selecting superior genotype for each specific target environment or avoided by selecting widely adapted and stable genotype across wide range of environments [6].

Through determining GEI effects, several methods of estimating phenotypic stability and adaptability are often used [7, 8]. However, the additive main effects and multiplicative interaction (AMMI) [9] and the genotype main effects plus genotype by environment interaction effects (GGE-Biplot) [10] are the two most frequently used tools for multi-environment trials data analysis. Hence, the present 
experiment was executed to evaluate the performance and stability of introduced upland rice genotypes for wider and /or specific recommendation for cultivation in North-West Ethiopia.

\section{MATERIALS AND METHODS}

\section{Planting Materials, Experimental Design and Test Locations}

Including one check, a total of 16 introduced (from Africa Rice Centre) upland rice genotypes (Table 2) were evaluated from 2010 to 2012 at four locations consisting of eight environments. The locations where the trials were conducted differ in soil type, altitude, temperature, rainfall received per annum (Table 1). At each location, the trial was laid out in a randomized complete block design (RCBD) of three replications. Each plot had six rows of $5 \mathrm{~m}$ long with spacing of $0.2 \mathrm{~m}$ between rows. Fertilizer (UREA and DAP) was applied as per the recommendation of each respective location. Total DAP was applied at planting while urea was applied one third at planting, one third at tillering and the remaining one third at panicle initiation. Seed rate of $60 \mathrm{~kg} \mathrm{ha}^{-1}$ was used and seeds were directly drilled in a row. Plantings were done in the main rainy season following the optimal dates in each respective location.

Table 1. Description of experimental locations.

\begin{tabular}{|c|c|c|c|c|c|c|c|}
\hline \multirow[t]{2}{*}{ Location } & \multirow{2}{*}{$\begin{array}{l}\text { Elevation } \\
\text { (m) }\end{array}$} & \multirow[t]{2}{*}{ Latitude } & \multirow[t]{2}{*}{ Longitude } & \multirow{2}{*}{$\begin{array}{l}\text { Annual rain } \\
\text { fall }(\mathrm{mm})\end{array}$} & \multicolumn{2}{|c|}{ Mean temperature $\left({ }^{\circ} \mathrm{C}\right)$} & \multirow[t]{2}{*}{ Soil type } \\
\hline & & & & & Min. & Max. & \\
\hline Woreta & 1810 & $11^{0} 58^{\prime} \mathrm{N}$ & $37^{0} 41^{\prime} \mathrm{E}$ & 1300 & 11.5 & 27.9 & vertisol \\
\hline Pawe & 1050 & $11^{0} 9^{\prime} \mathrm{N}$ & $36^{0} 3^{\prime} \mathrm{E}$ & 1457 & 17.2 & 32.7 & cambisol \\
\hline Metema & 750 & $12^{\circ} 54 \mathrm{~N}$ & $36^{\circ} 15 \mathrm{E}$ & 1100 & 22 & 29 & vertisol \\
\hline Maitsebri & 1350 & $13^{\circ} 05 \mathrm{~N}$ & $38^{\circ} 08 \mathrm{E}$ & 1296 & 15 & 36 & vertisol \\
\hline
\end{tabular}

Source: [11] and [12]

Table 2. Genotypes used in the study.

\begin{tabular}{|l|l|l|l|}
\hline No & Genotype & Genotype code & Source \\
\hline 1 & ARCCU3Fa9-L6P1-B-B-2 & G1 & AfricaRice \\
\hline 2 & ARCCU12Fa1L4P7-19-1-1-B1 & G2 & AfricaRice \\
\hline 3 & ARCCU12Fa1L6P7-19-1-1-1-B1 & G3 & AfricaRice \\
\hline 4 & ARCCU3Fa11-L1P1-B-B-1 & G4 & AfricaRice \\
\hline 5 & ARCCU3Fa6-L3P9-B-B-3 & G5 & AfricaRice \\
\hline 6 & ARCCU12Fa1L6P7-2-1-1-2-B & G6 & AfricaRice \\
\hline 7 & ARCCU12Fa1L6P7-24-1-1-2-B & G7 & AfricaRice \\
\hline 8 & ARCCU12Fa1L6P7-2-1-1-3-B & G8 & AfricaRice \\
\hline 9 & ARCCU2Fa11-L2P1-B-B-1 & G9 & AfricaRice \\
\hline 10 & WAB880-1-38-20-17-P1-HB & G10 & AfricaRice \\
\hline 11 & WAB450-1-B-P-462-HB & G11 & AfricaRice \\
\hline 12 & WAB878-6-37-5-1-P1-HB & G12 & AfricaRice \\
\hline 13 & WAB878SG41 & G13 & AfricaRice \\
\hline 14 & WAB880-1-32-1-2-P1-HB & G14 & AfricaRice \\
\hline 15 & IRAT112 & G15 & AfricaRice \\
\hline 16 & AD048 (check) & G16 & Adet research centre \\
\hline
\end{tabular}

\section{Data Collection and Statistical Analysis}

Data were collected for days to heading, days to maturity, panicle length, plant height, filled grains/panicle, fertile tillers/plant, grain yield, and 1000 seed weight. Grain yield ( $\mathrm{h} \mathrm{ha}^{-1}$ ) was estimated based on adjustment at $14 \%$ moisture level on the basis of four central harvestable rows. The grain yield and other agronomic parameters were subjected to analysis of variance using the SAS version 8.1software. The grain yield data were also subjected to the Additive Main Effect and Multiplicative Interaction (AMMI) analysis. The GGE-biplot analysis was also used for ranking genotypes based on grain yield performance and stability and also for detecting wider and /or specifically adapted genotype(s).

\section{RESULTS AND DISCUSSION}

\section{Analysis of Variance and Agronomic Performance}

The combined analysis of variance for grain yield and other agronomic characters showed significant differences $(\mathrm{P} \leq 0.01)$ due to main effects such as genotypes and test locations. The analysis for year 
effect also revealed significant variation $(\mathrm{P} \leq 0.01)$ among genotype in terms of all characters except in grain yield (Table 3 ). The genotype $\mathrm{x}$ location interaction effect was significant $(\mathrm{P} \leq 0.01)$ for days to heading, days to maturity, panicle length, plant height and grain yield whereas genotype $\mathrm{x}$ year interaction found to be significant only for days to heading, days to maturity and plant height. On the other hand the location $\mathrm{x}$ year interaction showed significant variation $(\mathrm{P} \leq 0.01)$ for all characters considered. Significant effect of location x year interaction emphasizes that influence of locations on grain yield of rice genotypes during years are obviously different.

The three way interaction of genotype $\mathrm{x}$ location $\mathrm{x}$ year revealed significant variation $((\mathrm{P} \leq 0.01)$ only in days to heading, panicle length, filled grains per panicle and grain yield (Table 3 ). The significant genotype $\mathrm{x}$ location $\mathrm{x}$ year interaction effects for grain yield demonstrated that genotypes responded differently to the variation in locations and years indicating the necessity of testing rice genotypes at multiple locations and over yeas

Table 3. Combined mean grain yield and yield related parameters of 16 upland elite rice genotypes evaluated at four locations from 2010 to 2012 cropping seasons in North west Ethiopia

\begin{tabular}{|c|c|c|c|c|c|c|c|c|c|c|}
\hline No & Genotype & Code & DTH & DTM & PL(cm) & $\mathbf{P H}(\mathbf{c m})$ & FGP & FTP & $\begin{array}{l}\text { GY } \\
\text { (kg/ha) }\end{array}$ & TSW $(g)$ \\
\hline 1 & ARCCU3Fa9-L6P1-B-B-2 & G1 & $79.0 \mathrm{~cd}$ & $115.0 \mathrm{bcd}$ & $27.5 \mathrm{ab}$ & $78.4 \mathrm{~b}$ & 96.4de & $4.7 f$ & $3035 . b$ & $28.3 \mathrm{bcd}$ \\
\hline 2 & ARCCU12Fa1L4P7-19-1-1-B1 & G2 & $74.0 \mathrm{~h}$ & $114.5 \mathrm{bcd}$ & $23.2 \mathrm{ef}$ & $66.3 \mathrm{gh}$ & $87.4 \mathrm{e}$ & $5.7 \mathrm{bc}$ & $2099.5 \mathrm{de}$ & $24.6 \mathrm{ij}$ \\
\hline 3 & $\begin{array}{l}\text { ARCCU12Fa1L6P7-19-1-1-1- } \\
\text { B1 }\end{array}$ & G3 & $74.8 \mathrm{gh}$ & $115.3 \mathrm{bc}$ & 23.3ef & $68.5 f g$ & $93.7 \mathrm{de}$ & 5.1cdef & $1929.5 \mathrm{e}$ & 25.0hi \\
\hline 4 & ARCCU3Fa11-L1P1-B-B-1 & G4 & 79.2 & $114.8 \mathrm{bcd}$ & $24.8 \mathrm{cde}$ & 70.6ef & $109.5 \mathrm{ab}$ & $6.1 \mathrm{~b}$ & $3975.8 \mathrm{a}$ & $29.2 \mathrm{ab}$ \\
\hline 5 & ARCCU3Fa6-L3P9-B-B-3 & G5 & $79.9 \mathrm{c}$ & $115.1 \mathrm{bc}$ & $24.7 \mathrm{de}$ & $74.6 \mathrm{~cd}$ & $95.6 \mathrm{de}$ & $4.8 \mathrm{ef}$ & $2288.6 \mathrm{~cd}$ & $26.4 \mathrm{fg}$ \\
\hline 6 & ARCCU12Fa1L6P7-2-1-1-2-B & G6 & $78.5 \mathrm{cde}$ & $114.3 \mathrm{bcd}$ & $25.7 \mathrm{bcd}$ & $77.4 \mathrm{bc}$ & $99.7 \mathrm{~cd}$ & $4.7 f$ & $2264.5 \mathrm{~cd}$ & 26.0fgh \\
\hline 7 & $\begin{array}{l}\text { ARCCU12Fa1L6P7-24-1-1-2- } \\
\text { B }\end{array}$ & G7 & 79.3 & $113.5 \mathrm{bcd}$ & 26.0abcd & $68.7 f g$ & $99.9 \mathrm{~cd}$ & $5.5 \mathrm{bcde}$ & $2365.7 \mathrm{~cd}$ & $24.0 \mathrm{j}$ \\
\hline 8 & ARCCU12Fa1L6P7-2-1-1-3-B & G8 & 78.0de & $114.3 \mathrm{bcd}$ & $27.0 \mathrm{ab}$ & $77.2 \mathrm{bc}$ & $102.1 \mathrm{bcd}$ & $4.7 f$ & $2225.8 \mathrm{cde}$ & $26.0 \mathrm{gh}$ \\
\hline 9 & ARCCU2Fa11-L2P1-B-B-1 & G9 & $84.0 \mathrm{~b}$ & $123.8 \mathrm{a}$ & $27.8 \mathrm{a}$ & $83.4 \mathrm{a}$ & $116.3 \mathrm{a}$ & $7.3 \mathrm{a}$ & $3853.3 \mathrm{a}$ & $29.2 \mathrm{ab}$ \\
\hline 10 & WAB880-1-38-20-17-P1-HB & 10 & $79.5 \mathrm{~cd}$ & $115.4 \mathrm{~b}$ & $24.5 \mathrm{de}$ & $72.3 \mathrm{de}$ & $94.7 \mathrm{de}$ & 5.0def & $3057.5 b$ & $30.0 \mathrm{a}$ \\
\hline 11 & WAB450-1-B-P-462-HB & G11 & $79.5 \mathrm{~cd}$ & $112.8 \mathrm{~d}$ & $24.5 \mathrm{de}$ & $71.4 \mathrm{ef}$ & $105.8 \mathrm{bc}$ & $6.1 \mathrm{~b}$ & $4085.8 \mathrm{a}$ & $28.0 \mathrm{cde}$ \\
\hline 12 & WAB878-6-37-5-1-P1-HB & G12 & $76.3 f g$ & $114.4 \mathrm{bcd}$ & $22.5 \mathrm{f}$ & $61.0 \mathrm{i}$ & $95.2 \mathrm{de}$ & 5.6bcd & $2484.6 \mathrm{c}$ & 25.6ghi \\
\hline 13 & WAB878SG41 & G13 & 77.0ef & $113.1 \mathrm{~cd}$ & $22.0 \mathrm{f}$ & 63.1hi & 95.1de & 5.1cdef & $2420.3 c$ & 25.0hi \\
\hline 14 & WAB880-1-32-1-2-P1-HB & G14 & $78.7 \mathrm{~cd}$ & $114.5 \mathrm{bcd}$ & $23.6 \mathrm{ef}$ & $67.2 \mathrm{~g}$ & 94.0de & 5.6bcd & $3169.0 \mathrm{~b}$ & $27.1 \mathrm{ef}$ \\
\hline 15 & IRAT112 & G15 & $80.0 \mathrm{c}$ & $114.3 \mathrm{bcd}$ & $22.4 \mathrm{f}$ & $66.5 \mathrm{~g}$ & $89.7 \mathrm{e}$ & 5.6bcd & $2482.4 \mathrm{c}$ & $29.0 \mathrm{abc}$ \\
\hline 16 & AD048 (check) & G16 & $91.6 \mathrm{a}$ & $124.4 \mathrm{a}$ & $26.7 \mathrm{abc}$ & $82.7 \mathrm{a}$ & $87.8 \mathrm{e}$ & $5.8 \mathrm{~b}$ & $3327.4 \mathrm{~b}$ & $27.2 \mathrm{def}$ \\
\hline & Mean & & 79.3 & 115.6 & 24.8 & 71.8 & 97.7 & 5.5 & 2816.5 & 26.8 \\
\hline & CV (\%) & & 3.67 & 3.29 & 13.24 & 7.86 & 16.52 & 22.44 & 19.62 & 7.58 \\
\hline & Genotype (G) & & $* * *$ & $* * *$ & $* * *$ & $* * *$ & $* * *$ & $* * *$ & $* * *$ & $* * *$ \\
\hline & Location (L) & & $* * *$ & $* * *$ & $* * *$ & $* * *$ & $* * *$ & $* * *$ & $* * *$ & $* * *$ \\
\hline & Year (Y) & & $* * *$ & $* * *$ & $* * *$ & $* * *$ & $* * *$ & $* * *$ & NS & $* * *$ \\
\hline & GX L & & $* * *$ & $* * *$ & $* * *$ & $* * *$ & NS & NS & $* * *$ & NS \\
\hline & $\mathbf{G} \times \mathbf{Y}$ & & $* * *$ & $* * *$ & $* * *$ & $* * *$ & $*$ & NS & NS & NS \\
\hline & $\mathbf{L} \times \mathbf{Y}$ & & $* * *$ & $* *$ & $* * *$ & $* * *$ & $* * *$ & $* * *$ & $* * *$ & $* *$ \\
\hline & $G \times L \times Y$ & & $* * *$ & NS & $* * *$ & NS & $* * *$ & NS & $* * *$ & NS \\
\hline
\end{tabular}

Note: $* * *, * * *$ significant at $5 \%, 1 \%$ and $0.1 \%$ respectively, $\mathrm{NS}=$ not significant, DTH=days to heading, $\mathrm{DTM}=$ days to maturity, $\mathrm{PL}=$ panicle length, $\mathrm{PH}=$ plant height, $\mathrm{FGP}=$ field grains per panicle, FTP=fertile tillers/plant, GY= grain yield $(\mathrm{kg} / \mathrm{ha}), \mathrm{TSW}=1000$ seed weight $(\mathrm{g})$.

Significant interaction differences of genotypes $\times$ year $\times$ location implied that application of stability analysis for identifying widely and/or specifically adapted rice genotype is essential. These results are in agreement with those of [13] and [14].

In the current study, as depicted by (Table 3), the overall agronomic performance of 16 genotypes seems good in terms of characters considered. The mean grain yield of 16 genotypes ranged from 1929.5 (G3) to 4085.8 $\mathrm{kgha}^{-1}(\mathrm{G} 11)$. The Genotypes G11, G4 and G9 with grain yield of 4085.8, 3975.8 and $3853.3 \mathrm{~kg} \mathrm{ha}^{-1}$, respectively were the three high yielding genotypes. Compared to the standard check (G16), the top high yielding three genotypes (G11, G4 and G9) gave grain yield advantage of $22.8 \%, 19.5 \%$ and $15.8 \%$, respectively. Of tested 16 genotypes, only these three genotypes performed significantly above the standard check. The three genotypes also performed better in terms of 1000 seed weight and in filed grains per panicle (Table 3). 


\section{AMMI Analysis of Variance for G X E Interaction}

The AMMI analysis is indicated in Table 4. The MMI analysis of variance for grain yield $\left(\mathrm{kg} \mathrm{ha}^{-1}\right)$ of 16 upland rice genotypes evaluated across eight environments revealed that the main effects of genotypes $(\mathrm{G})$ and environments (E) accounted for $53.8 \%$ and $26.8 \%$ of the treatment sum of squares, respectively. The $\mathrm{G} \times \mathrm{E}$ interaction also accounted for $19.4 \%$ of the treatment SS. The analysis showed that variations due to $\mathrm{G}, \mathrm{E}$ and $\mathrm{G} \times \mathrm{E}$ were significant $((\mathrm{P} \leq 0.001)$.

Table 4. AMMI analysis of variance for grain yield of 16 upland rice genotypes.

\begin{tabular}{|l|l|l|l|l|}
\hline Source & D.f & SS & MS & \% explained SS \\
\hline Total & 383 & 404064795 & 1054999 & \\
\hline Block & 16 & 9391336 & $586958^{* *}$ & \\
\hline Treatments & 127 & 325163496 & $2560342^{* * *}$ & \\
\hline Genotypes (G) & 15 & 175089532 & $11672635^{* * *}$ & 53.8 \\
\hline Environments(E) & 7 & 87116278 & $12445183^{* * *}$ & 26.8 \\
\hline G x E & 105 & 62957685 & $599597^{* * * *}$ & 19.4 \\
\hline IPCA 1 & 21 & 22441471 & $1068641^{* * *}$ & 35.6 \\
\hline IPCA 2 & 19 & 17061325 & $897964^{* *}$ & 27.1 \\
\hline IPCA 3 & 17 & 11184475 & $657910^{* * *}$ & 18.8 \\
\hline IPCA 4 & 15 & 4911284 & $327419 \mathrm{NS}$ & \\
\hline Residuals & 33 & 7359130 & $223004 \mathrm{NS}$ & \\
\hline Error & 240 & 69509964 & 289625 & \\
\hline
\end{tabular}

The large sum of squares for genotypes indicated that the genotypes were diverse, with large differences among genotypic means causing most of the variation in grain yield, which is in contrary with the findings of $[15,16,1]$, in which the environments exhibited larger sum of squares than that of the genotypes. The presence of $\mathrm{G} \times \mathrm{E}$ interaction (GEI) was clearly demonstrated by the AMMI model, when the interaction was partitioned among the first three interaction principal component axis (IPCA) as they were significant in predictive assessment (Table 4). The first and the second interaction PCA were highly significant $(\mathrm{P} \leq 0.001)$, capturing $35.6 \%$ and $27.1 \%$ of the total variation in the GxE interaction SS, respectively. The third interaction PCA was also significant $(\mathrm{P} \leq 0.01)$, capturing $18.8 \%$ of GE interaction SS while the forth interaction PCA was not significant. The first three interaction PCA axes jointly accounted for $81.5 \%$ of the GxE interaction SS (Table 4).

\section{AMMI Stability Analysis and Grain Yield Performance}

In the current study, inconsistency in grain yield ranking was observed from environment to environment (Table5) which indicated the presence of possible crossover $\mathrm{G} \times \mathrm{E}$ interaction as described by Yan and hunt (2001). It is commonly reported that multi-environment data may constitute a mixture of crossover and non-crossover types of $\mathrm{G} \times \mathrm{E}$ interaction in which the former indicated the change in yield ranking of genotypes across environments and the later shows constant yield rankings of genotypes across environments $[17,18]$. The environments mean grain yield ranged from 2131.1 for E7 to $3494.3 \mathrm{kaha}^{-1}$ for E2 (Table 5).

In AMMI-I biplot (Figure1), If a genotype or an environment has a IPCA1 score of nearly zero, it has small interaction effects and considered as stable. When a genotype and environment have the same sign on the PCA axis, their interaction is positive and if different, their interaction is negative [19]. Genotypes and environments on the same parallel lines have similar yields and a genotype or environment on the right side of the midpoint of this axis has higher yields than those of left hand side. Accordingly, among the upland rice genotypes, G11, G1, G4, and G10 generally exhibited high yield of positive IPCA1 score, out of which G11 and G1 had high IPCA1 scores in which G11 being the overall best genotype. Hence, the G11 was identified as specially adapted and the highest yielding genotype to the corresponding environments (Figure 1). On the other hand G9, G16 and G14 were high yielding genotypes with negative IPCA1 scores. Of 16 genotypes, G9, G10, G8, G15, G2, G6 and G13 were with near zero IPCA scores and hence have less interaction with the environments out of which only G9 and G10 had above average yield performance. Among environments, E6, E3, E4, and E8 exhibited near zero IPCA1 score and hence had small interaction effects indicating that all the genotypes performed well in these locations. Of the environments, however, E6 and E3 were most favorable environments for most genotypes while E2, E7 and E1 were good for only few genotypes[20] and [21] reported similar pattern of interactions 
Evaluation of Performance and Yield Stability Analysis Based on AMMI and GGE Models in Introduced Upland Rice Genotypes Tested Across Northwest Ethiopia

Table 5. Predicted mean yield estimates of 16 upland rice genotypes across eight environments and stability indicators of AMMI analysis

\begin{tabular}{|c|c|c|c|c|c|c|c|c|c|c|c|c|c|}
\hline No & Genotype & Code & E1 & E2 & E3 & E4 & E5 & E6 & E7 & E8 & Mean & IPCA1 & IPCA2 \\
\hline 1 & ARCCU3Fa9-L6P1-B-B-2 & G1 & 2910 & 2985 & 3002 & $\underline{3117}$ & 3320 & 3297 & 2644 & 3005 & 3035.0 & 17.945 & -10.915 \\
\hline 2 & ARCCU12Fa1L4P7-19-1-1-B1 & G2 & 1425 & 3135 & 3531 & 1632 & 2263 & 2232 & 1732 & 2303 & 2281.6 & -2.906 & -18.299 \\
\hline 3 & ARCCU12Fa1L6P7-19-1-1-1-B1 & G3 & 1299 & 2286 & $\underline{4464}$ & 1610 & 1952 & 2355 & 2018 & 1836 & 2227.5 & 10.349 & -10.658 \\
\hline 4 & ARCCU3Fa11-L1P1-B-B-1 & G4 & $\underline{4290}$ & 3930 & 2328 & $\underline{3823}$ & $\underline{4281}$ & $\underline{5099}$ & $\underline{2949}$ & $\underline{3242}$ & 3742.8 & 15.178 & 11.896 \\
\hline 5 & ARCCU3Fa6-L3P9-B-B-3 & G5 & 1698 & 2819 & 2594 & 1695 & 2605 & 3204 & 1689 & 2467 & 2346.4 & 5.450 & -6.968 \\
\hline 6 & ARCCU12Fa1L6P7-2-1-1-2-B & G6 & 1624 & 2665 & 3925 & 2307 & 1789 & 3062 & 1691 & 2298 & 2420.1 & 2.819 & 2.757 \\
\hline 7 & ARCCU12Fa1L6P7-24-1-1-2-B & G7 & 1960 & 3666 & 3331 & 2189 & 2245 & 2524 & 1328 & 2400 & 2455.4 & -12.164 & -8.634 \\
\hline 8 & ARCCU12Fa1L6P7-2-1-1-3-B & G8 & 1337 & 2739 & 3927 & 2102 & 1888 & 3458 & 1781 & 1881 & 2389.1 & 0.775 & 6.486 \\
\hline 9 & ARCCU2Fa1 1-L2P1-B-B-1 & G9 & $\underline{3948}$ & $\underline{4943}$ & 2075 & 2993 & $\underline{3948}$ & $\underline{4424}$ & $\underline{3111}$ & $\underline{3160}$ & 3575.3 & -4.034 & 3.536 \\
\hline 10 & WAB880-1-38-20-17-P1-HB & G10 & 2775 & 3369 & 2079 & 3043 & 2681 & 4152 & 2107 & 2802 & 2876.0 & 3.798 & 12.126 \\
\hline 11 & WAB450-1-B-P-462-HB & G11 & $\underline{4408}$ & 3811 & $\underline{4192}$ & $\underline{3652}$ & $\underline{3952}$ & $\underline{4614}$ & $\underline{3713}$ & $\underline{4071}$ & 4051.6 & 21.996 & 4.239 \\
\hline 12 & WAB878-6-37-5-1-P1-HB & G12 & 1151 & 3919 & 2132 & 2859 & 2667 & 2878 & 1639 & 2437 & 2460.3 & -16.394 & -19.786 \\
\hline 13 & WAB878SG41 & G13 & 1819 & 3080 & 2680 & 2595 & 2547 & 2806 & 2094 & 2056 & 2459.6 & 2.689 & -10.458 \\
\hline 14 & WAB880-1-32-1-2-P1-HB & G14 & 2322 & $\underline{4819}$ & 2614 & 2813 & 2407 & 3944 & 2194 & 2700 & 2976.6 & -23.873 & 8.047 \\
\hline 15 & IRAT112 & G15 & 1825 & 2777 & 2620 & 2119 & 1496 & 4170 & 1822 & 2320 & 2393.6 & 1.156 & 24.980 \\
\hline 16 & AD048 (check) & G16 & 3198 & $\underline{4964}$ & $\underline{4300}$ & 2972 & 2982 & 4128 & 1586 & 2863 & 3374.1 & -22.784 & 11.651 \\
\hline & Mean & & 2374.3 & 3494.2 & 3112.1 & 2595.1 & 2688.9 & 3521.7 & 2131.1 & 2615.1 & & & \\
\hline & IPCA1 & & 16.353 & -44.026 & -6.661 & -0.081 & 10.193 & 1.669 & 19.150 & 3.403 & & & \\
\hline & IPCA2 & & 12.991 & -9.148 & 20.731 & -6.546 & -21.539 & 29.332 & -13.919 & -11.902 & & & \\
\hline
\end{tabular}

E1= Woreta2010, E2= Pawe2010, E3= Woreta=2011, E4= Metema2011, E5= Pawe2011, E6= Woreta2012, E7 $=$ Pawe2012, E8= Maitsebri2012

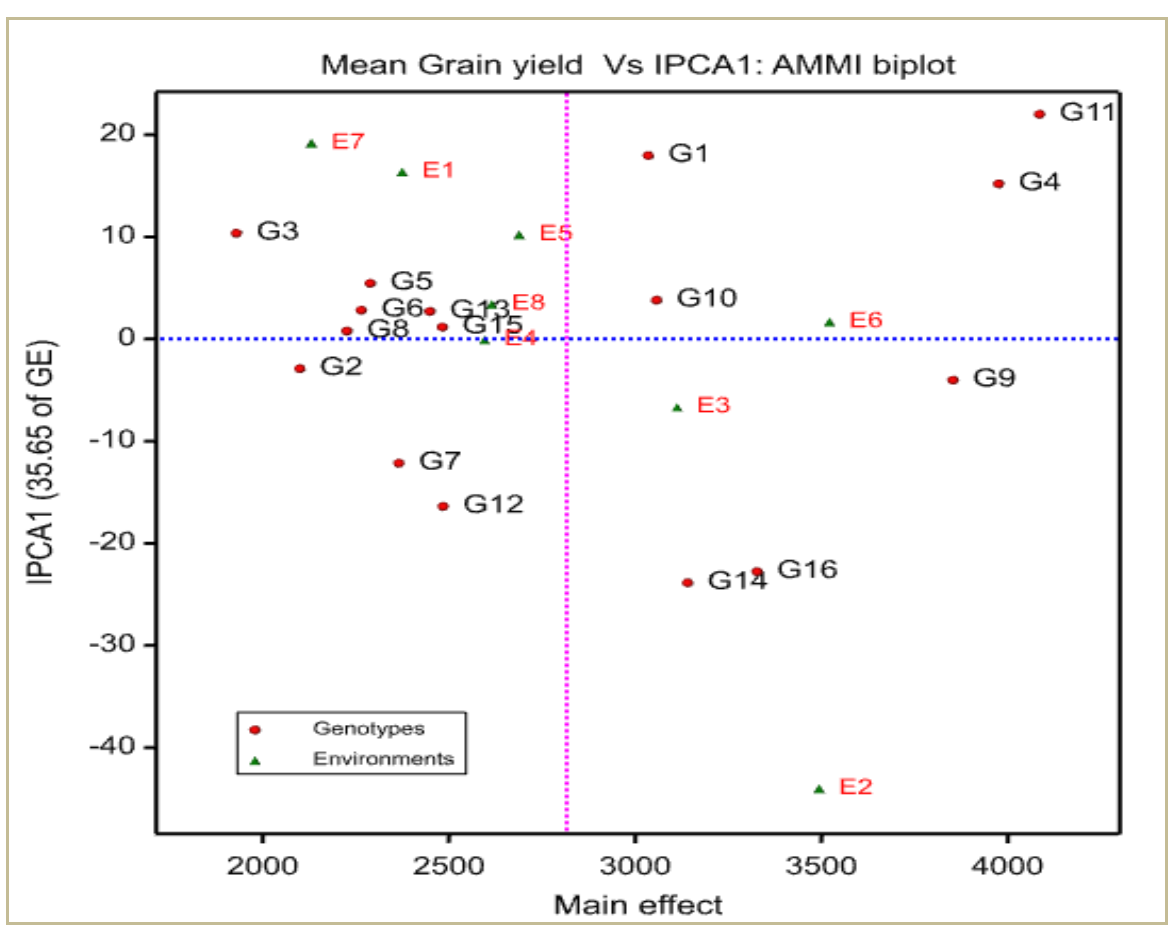

Figure 1. AMMI biplot for grain yield $\left(\mathrm{kg} \mathrm{ha}^{-1}\right)$ of sixteen upland rice genotypes $(G)$ and eight environments $(E)$ using genotypic and environmental scores. $\{E 1=$ Woreta2010, E2= Pawe2010, E3= Woreta=2011, E4= Metema2011, E5= Pawe2011, E6= Woreta2012, E7=Pawe2012, E8= Maitsebri2012\}

In AMMI 2 biplot (Figure2), the environmental scores are joined to the origin by side lines. Sites with short spokes do not exert strong interactive forces. Those with long spokes exert strong interaction. Hence, environments E2, E6, E7 and E3 exerted strong interaction forces while the rest four did less. On the other hand, the genotypes near the origin are not sensitive to environmental interaction and 
those distant from the origins are sensitive and have large interaction. In the present study, G11,G15, G2, G1, G12, G14 and G16 had more responsive since they were away from the origin whereas the genotypes G8, G4, G10, G6, G9, G5, G3, G13 and G7 were close to the origin and hence they were less sensitive to environmental interactive forces while genotypes G9, G6 and G8 were the most closest to the origin and hence had almost no interaction forces.

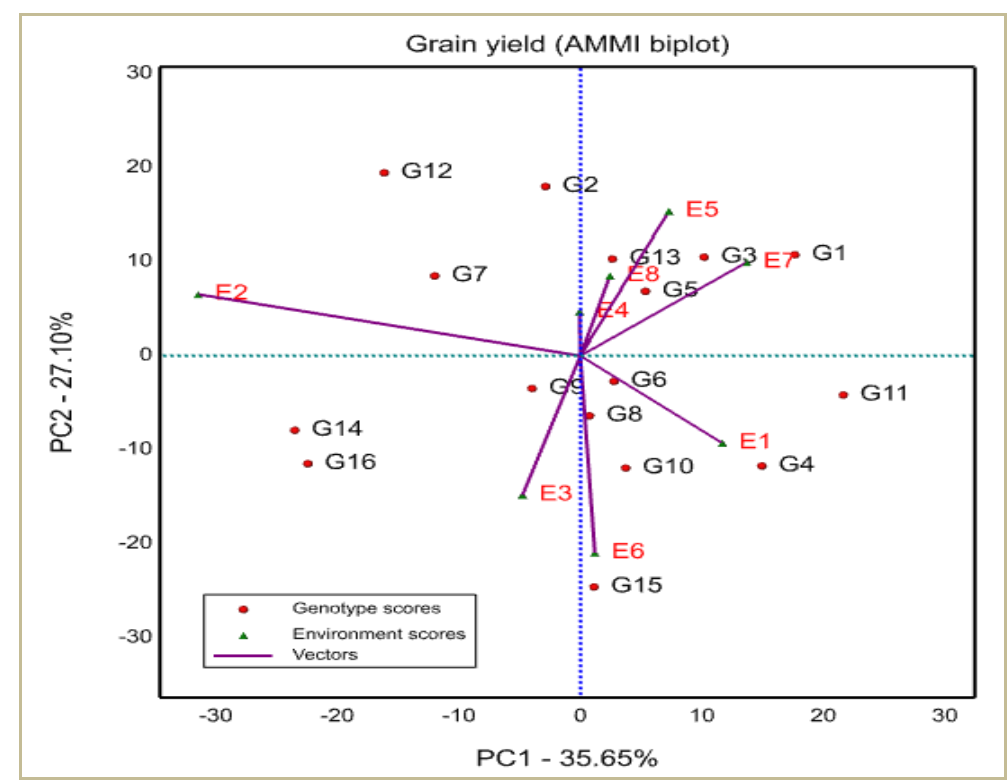

Figure 2. AMMI-II biplot for grain yield $\left(\mathrm{kg} \mathrm{ha}^{-1}\right)$ showing the interaction of PC1 against PC2 scores of sixteen upland rice genotypes $(G)$ and eight environments $(E) . \quad\{E 1=$ Woreta2010, E2 $=$ Pawe2010, E3= Woreta $=2011$, E4= Metema2011, E5= Pawe2011, E6= Woreta2012, E7= Pawe2012, E8= Maitsebri2012 $\}$

\section{GGE bi-plot Analysis}

GGE bi-plot can best identify $\mathrm{G}$ x E interaction pattern of data and clearly shows which genotypes performs best in which environments, and thus facilitates mega-environment identification than AMMI. Otherwise, both GGE and AMMI models are equivalent as far as their accuracy is concerned [22]. The polygon view of the GGE bi-plot (shown in figure 3 ) indicates the best genotype(s) in each environment[10]. The vertex genotypes (G11, G9, G16, G7 and G3) have the longest vectors, in their respective direction, which is a measure of responsiveness to environments. The vertex genotypes for each sector are the ones that gave the highest yield for the environments that fall within that sector. The genotype with the high yield in E7, E5, E4, E6, E3, E8 and E1 environments is G11, followed by G4, G9. In E2 the best genotypes is G14. The other vertex genotypes (G7 and G3), are poorest in all environments because there is no location in their sectors.

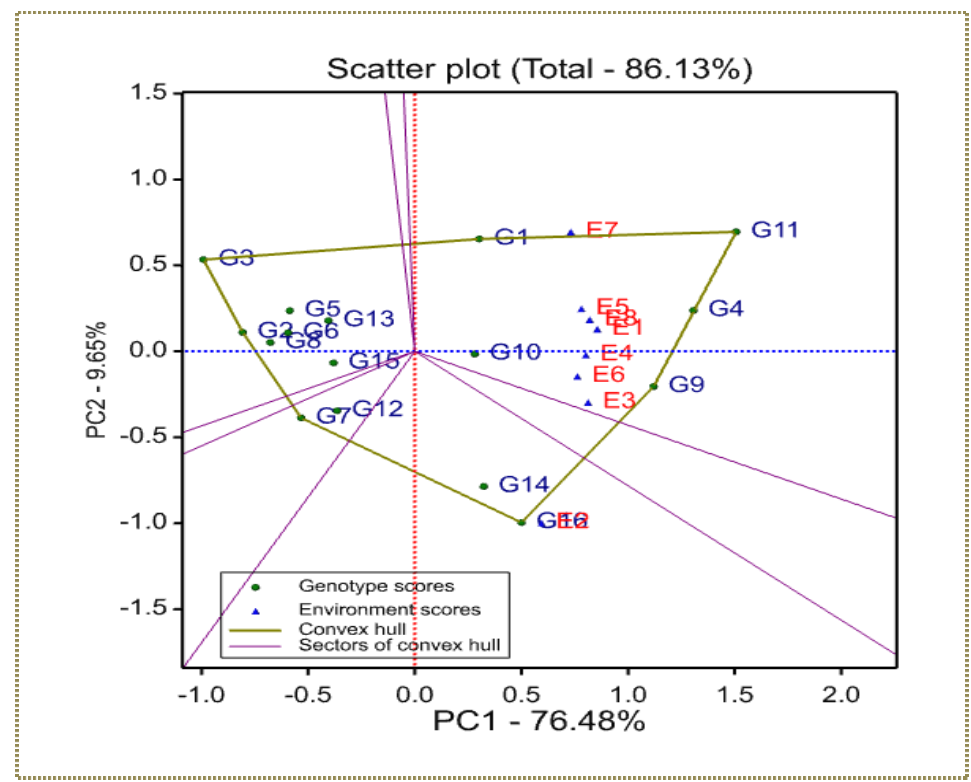

Figure 3. GGE-biplot showing upland rice genotypes with respect to the environments 


\section{Mean Grain Yield and Stability Performance}

The ranking of 16 upland rice genotypes based on their mean yield and stability performance are shown in Figure 4. The line passing through the bi-plot origin is called the average tester coordinate (ATC), which is defined by the average PC1 and PC2 scores of all environments [23]. The line which passes through the origin and is perpendicular to the ATC represents the stability of genotypes. Either direction away from the bi-plot origin on this axis indicates greater GE interaction and reduced stability. For selection, the ideal genotypes are those with both high mean yield and high stability. In the bi-plot, they are close to the origin and have the shortest vector from the ATC.

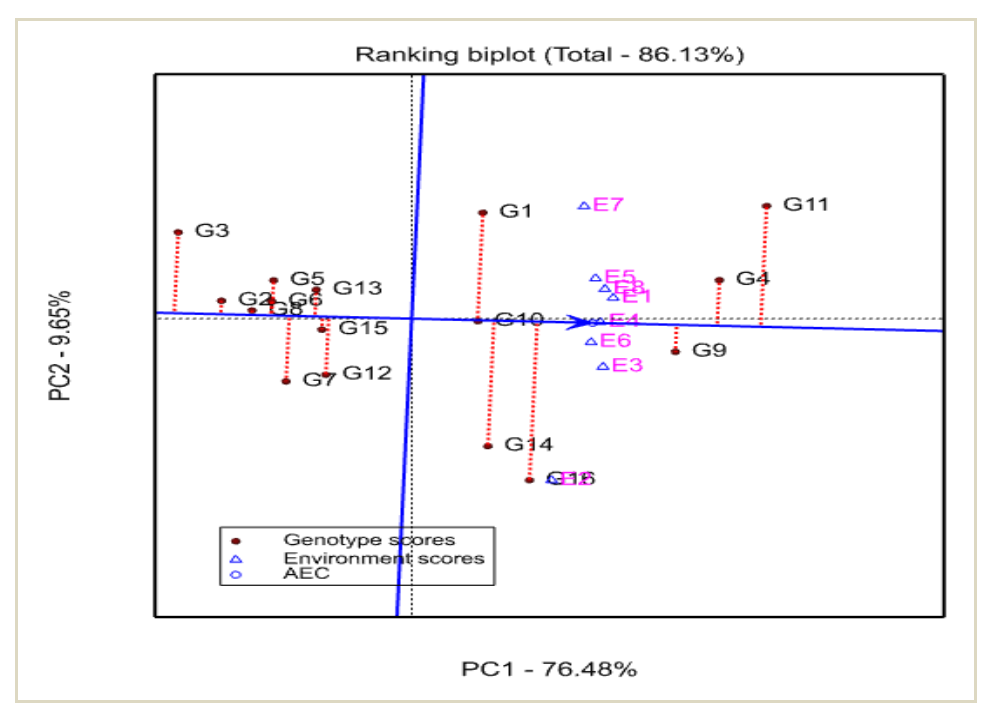

Figure 4. Ranking genotypes based on mean grain yield and stability across environments

As shown in Figure 4, the genotype G4, followed by G9, can be considered as genotypes with both high yield and stability performance. The genotypes with highest yielding performance but relatively with low stability was G11, whereas the genotypes with low yield and low stability were G16, G14, and G1. The other genotypes on the right side of the line with no arrow have yield performance greater than mean yield and the genotypes on the left side of this line had yields less than mean yield. Of the genotypes, G10 was the most stable, followed by G9 with better mean yield performance. According to this bi-plot (Figure 4), G11 can be recommended for specific adaptation whereas G4 and G9 relatively for wider adaptation.

\section{CONCLUSION AND RECOMMENDATION}

The results indicated that yield performance of upland rice genotypes were influenced by GE interaction effect, the environments and genotypes as well. Grain yield is a complex trait that is affected by a number of component characters along with the environment directly or indirectly. AMMI and GGE statistical models could be a great tool to select the most suitable and stable high yielding genotypes for specific as well as for diverse environments. In the present study, AMMI model has shown that the largest proportion of the total variation in grain yield was attributed to genotypes and somehow to environments. GGE bi-plot analysis also allowed to visualize the winner genotype at each sector and to identify high yielding and stable genotypes. The mean grain yield value of genotypes averaged over environments indicated that G11 had the highest (4085.8 $\mathrm{kgha}^{-1}$ ), followed G4 with grain yield of $3975.8 \mathrm{kgha}^{-1}$. As revealed by AMMI and GGE bi-plots, the genotype G11 was identified as specifically adapted to Fogera (Woreta areas). This is in line with the recommendation of the National Variety Release Committee of Ethiopia. The committee declare its decision on G11 to use as variety based on mean yield performance and farmers feedback. Therefore, G11 could be popularized in wider scale in Fogera and in other ecologies of similar conditions.

\section{ACKNOWLEDGEMENT}

The authors would like to acknowledge the Amhara Regional Agricultural Research Institute (ARARI) and Ethiopian Institute of Agricultural Research Institute (EIAR) for financially supporting the execution of this experiment. The technical staffs of rice improvement sections at Pawe, Gondar, Mai-Tsebri and Adet research centers are highly appreciated. 


\section{REFERENCES}

[1] Ministry of Agriculture and Rural Development (MoA), (2010). National Rice Research and Development Strategy of Ethiopia. Addis Ababa, Ethiopia, pp. 48.

[2] Heluf Gebrekidan and Mulugeta Seyum.2006. Effects of Mineral N and P Fertilizers on Yield and Yield Components of Flooded Lowland Rice on Vertisols of Fogera Plain, Ethiopia. Journal of Agriculture and Rural Development in the Tropics and Subtropics, 107(2): 161-176.

[3] Zu, Y. (2010). Stability and adaptability of upland rice genotypes . Crop breeding and applied biotechnology 10:357-363.

[4] Kang, Y, (1993). GGE-biplot analysis of multi-environment yield trials in bread wheat. Turk J. Agric. 30:325-337.

[5] Comestock, F.and Moll, M.(1963). A comparison of univariate and multivariate methods to analyze environments. Field Crops Res 56:271-286.

[6] Ceccarelli S (1996). Adaptation to low or high input cultivation. Euphytica 92:203-214.

[7] Crossa, J. 1990. Statistical analysis of multi-location trials. Advances in Agronomy 44:55-85

[8] Gauch G. 1992. Statistical Analysis of Regional Yield Trials: AMMI Analysis of Factorial Designs. Elsevier Science Publishers, Amsterdam, the Netherlands.

[9] Gauch HG, Piepho HP, Annicchiarico P (2008). Statistical analysis of yield trials by AMMI and GGE: Further considerations. Crop Sci 48:866-889.

[10] Yan W, Hunt LA (2002). Biplot analysis of diallel data. Crop Sci 42:21-30.

[11] Taddesse L, Sewagegne T, Teferi A and Mulugeta B. 2014 Agronomic performances and stability analysis of upland rice genotypes in North West Ethiopia. International Journal of Scientific and Research Publication 4(4): 1-9

[12] Alem Redda and Fetien Abay,2015. Agronomic Performance of Integrated Use of Organic and Inorganic Fertilizers on Rice (Oryza sativa L.) in Tselemti District of North-Western Tigray, Ethiopia. Journal of Environment and Earth Science, Vol.5, No.9, 2015

[13] Dorosti, H., R. Honarnejad and M.S. Mohammad-Salehi, 1997. Determination of stability and adaptability of rice cultivars in different environmental conditions. Explants and Seeds, 4: 30-4

[14] Honarnejad, R., S. Abdollahi, M.S. Mohammad-Salehi and H. Dorosti, 2000. Consideration of adaptability and stability of grain yield of progressive rice (Oryza sativa L.) lines. Res. Agric. Sci.1: $1-9$

[15] Misra RC, Das S, Patnaik MC (2009) AMMI Model Analysis of Stability and Adaptability of Late Duration Finger Millet (Eleusine coracana) Genotypes. World Applied Sciences Journal 6: 1650- 1654.

[16] Fentie M, Assefa A, Belete K (2013) Ammi Analysis of Yield Performance and Stability of Finger Millet Genotypes Across Different Environments. World Journal of Agricultural Sciences 9: 231-237.

[17] Yan, W and L.A. Hunt. (2001). Interpretation of genotype $x$ environment interaction for winter wheat yield in Ontario. Crop Sci. 41: 19-25.

[18] Matus-Cadiz MA, Hucl P, Perron CE, Tyler RT (2003) Genotype x environment interaction for grain color in hard white spring wheat. Crop Sci 43: 219-226

[19] Zobel RW, Wright MJ, Gauch HG (1988) Statistical analysis of a yield trial. Agronomy Journal.80: 388-393.

[20] Adugna A (2007) Assessment of Yield Stability in Sorghum. African Crop Science Journal. 15: 83-92.

[21] Anandan A, Eswaran R, Sabesan T, Prakash M (2009) Additive main effects and multiplicative interactions analysis of yield performances in rice genotypes under coastal saline environments. Advances in Biological Research 3: 43-48.

[22] Yan, W., L.A. Hunt, Q. Sheng and Z. Szlavnics. (2000). Cultivar evaluation and megaenvironment investigation based on the GGE biplot. Crop Sci. 40: 597-605.

[23] Yan W, and MS Kang (2003) GGE biplot analysis: A graphical tool for breeders, geneticists, and agronomists. CRC Press, Boca Raton, FL. 